\title{
Editorial: Advances in Planning for Emerging Transportation Technologies: Towards Automation, Connectivity, and Electric Propulsion
}

\author{
Samuel Labi ${ }^{1 *}$, Panagiotis Anastasopoulos ${ }^{2,3}$, Mohammad Miralinaghi ${ }^{1}$, Ghim Ping Ong \\ and Feng $\mathrm{Zhu}^{5}$
}

${ }^{1}$ Center for Connected and Automated Transportation, and Lyles School of Civil Engineering, Purdue University, West Lafayette, IN, United States, ${ }^{2}$ Department of Civil, Structural and Environmental Engineering, University at Buffalo, Buffalo, NY, United States, ${ }^{3}$ Stephen Still Institute for Sustainable Transportation and Logistics, Buffalo, NY, United States, ${ }^{4}$ Department of Civil and Environmental Engineering, National University of Singapore, Singapore, Singapore, ${ }^{5}$ School of Civil and Environmental Engineering, Nanyang Technological University, Singapore, Singapore

Keywords: connected and autonomous vehicles, electric vehicles, managed lanes, advanced urban air mobility, flying cars, travel time variability, real-time traffic information, social media

Editorial on the Research Topic

Advances in Planning for Emerging Transportation Technologies: Towards Automation, Connectivity, and Electric Propulsion

\section{OPEN ACCESS}

Edited and reviewed by:

Sakdirat Kaewunruen,

University of Birmingham, United Kingdom

*Correspondence: Samuel Labi labi@purdue.edu

Specialty section: This article was submitted to Transportation and Transit Systems,

a section of the journal Frontiers in Built Environment

Received: 09 February 2021 Accepted: 19 February 2021 Published: 23 March 2021

Citation:

Labi S, Anastasopoulos P, Miralinaghi $M$, Ong GP and Zhu $F$ (2021) Editorial: Advances in Planning for Emerging Transportation Technologies: Towards Automation, Connectivity, and Electric Propulsion.

Front. Built Environ. 7:666246. doi: 10.3389/fbuil.2021.666246

\section{BACKGROUND}

Transportation systems continue to face significant challenges and opportunities in the context of their social, technical, and economic outcomes (De Neufville and Scholtes, 2011; Kaewunren et al.; Sinha et al., 2017; De Martinis and Corman, 2018; Bongiovanni et al., 2019; Eker et al., 2019; Eker et al., 2020a; Barmpounakis and Geroliminis, 2020; Becker et al., 2020; Eker et al., 2020b; Ahmed et al., 2021). A case in point is the set of ongoing advancements in information and computer technology that offer unprecedented opportunities for realizing or enhancing systems autonomy/automation, and connectivity. These developments continue to lay the building blocks for a new and exciting generation of transportation vehicles and associated infrastructure. This new transformative generation is expected to be characterized by vehicle connectivity and autonomy, emergent transport modes, new operational policies and standards, and enhanced economic productivity. From a social outcomes' perspective, the need for emissions reduction is motivating the promotion of electric propulsion of vehicles, a feature that is particularly indispensable for efficient operations of connected and autonomous vehicles (CAVs). This special issue crystallizes current thinking and future directions regarding some aspects of the science, engineering, and economic issues associated with the development of CAVs and related technologies.

\section{MAJOR HIGHLIGHTS OF CONTRIBUTIONS}

The articles in this special issue addressed the outcomes of next-generation transportation from perspectives that include safety, social and equity concerns (Ahmed et al.; Seilabi et al.) technical concerns in terms of mobility and reliability (Rahman et al.; Büchel and Corman; Ha et al.), economic considerations (Seilabi et al.), and outcomes associated with overall sustainability (Ahmed et al.; Seilabi 
et al.). Some of the articles in this special issue addressed the issue of transportation demand. For example, Seilabi et al. modeled traveler choices at different levels of market penetration of new technologies as a basis for measuring travel flows and establishing optimal levels of travel credit pricing, and Ahmed et al. explored public perceptions and potential benefits and concerns of a new transport mode, the flying car. In addition, some of the articles recognized that the nextgeneration technologies will exist not on their own but as part of an amalgamation of concepts so that synergistic benefits can be realized. For example, Ha et al. explained the possible holistic benefits of systems automation and systems connectivity towards transportation system efficiency and safety.

The articles in the special issue showed consistency with the concept of smart cities, a concept that is intertwined with new transportation technologies (Shaheen et al., 2019). This includes the automation and connectedness of smart city entities such as its vehicles (Ha et al.) citizenry, infrastructure and services. Seilabi et al. explained how travelers can use vehicle automation/connectivity features to honor travel credits at specific locations or times-of-day consistent with their lane type and link choices. Ahmed et al. examined the viability of advanced air vehicles to overcome persistent urban problems of traffic congestion and road disrepair.

The articles in the special issue also provided some guidance on future directions for investments and policy to promote the next generation of transportation systems. Ha et al. discussed how the current and future synergies between systems connectivity and autonomy could help generate knowledge that could be used to justify investments related to these technologies. Ahmed et al. offered insights that can inform next-generation policies and standards associated with the gradual advancement of advanced air vehicles and urban air mobility. Seilabi et al. demonstrated how the

\section{REFERENCES}

Ahmed, S. S., Fountas, G., Eker, U., Still, S. E., and Anastasopoulos, P. C. (2021). An exploratory empirical analysis of willingness to hire and pay for flying taxis and shared flying car services. J. Air Transp. Manag. 90, 101963. doi:10.1016/j.jairtraman.2020.101963

Barmpounakis, E., and Geroliminis, N. (2020). On the new era of urban traffic monitoring with massive drone data: the pNEUMA large-scale field experiment. Transp. Res. C: Emerging Tech. 111, 50-71. doi:10.1016/j.trc.2019.11.023

Becker, H., Becker, F., Abe, R., Bekhor, S., Belgiawan, P. F., Compostella, J., et al. (2020). Impact of vehicle automation and electric propulsion on production costs for mobility services worldwide. Transp. Res. A Policy Pract. 138, 105-126. doi:10.1016/j.tra.2020.04.021

Bongiovanni, C., Kaspi, M., and Geroliminis, N. (2019). The electric autonomous dial-aride problem. Transp. Res. B Methodol. 122, 436-456. doi:10.1016/j.trb.2019.03.004

De Martinis, V., and Corman, F. (2018). Data-driven perspectives for energy efficient operations in railway systems: current practices and future opportunities. Transp. Res. Part C Emerg. Technol. 95, 679-697. doi:10. 1016/j.trc.2018.08.008

de Neufville, R., and Scholtes, S. (2011). Flexibility in engineering design. Cambridge, MA: MIT Press.

Eker, U., Ahmed, S. S., Fountas, G., and Anastasopoulos, P. C. (2019). An exploratory investigation of public perceptions towards safety and security from the future use of flying cars in the United States. Anal. Methods Accid. Res. 23, 100103. doi:10.1016/j.amar.2019.100103 transportation agency can keep traditional vehicle travel costs to equitable levels, particularly during early periods of the transition towards the next-generation vehicles. Further, enhanced reliability in travel-time assessment due to enhanced modeling techniques (Büchel and Corman) or due to the use of social media data (Rahman et al.) can help transportation agencies and operators in their tasks of reporting, controlling operations, and disseminating information to not only shippers and travelers, but also to infrastructure planning and policy evaluation units in an agency.

\section{SUMMARY}

The articles in this special issue were motivated by advances in information and computer technology that in turn are fostering the development of automated and/or connected transportation systems or acquisition of information that will help realize this emerging generation transportation systems. The articles in the special issue addressed at least one of the following research activity areas associated with this emerging generation: travel demand assessments; policy and planning including assessments of impacts and their variability; road infrastructure management and network modeling to facilitate CAV adoption; alternative modes; and sharing of real-time information via connectivity of personal communication devices. The topic editors are grateful to the Specialty Chief Editor, Section Editors, and the Review Editors.

\section{AUTHOR CONTRIBUTIONS}

All authors listed made a substantial, direct and intellectual contribution to the work, and approved it for publication.

Eker, U., Fountas, G., and Anastasopoulos, P. C. (2020a). An exploratory empirical analysis of willingness to pay for and use flying cars. Aerosp. Sci. Technol. 104, 105993. doi:10.1016/j.ast.2020.105993

Eker, U., Fountas, G., Anastasopoulos, P. C., and Still, S. E. (2020b). An exploratory investigation of public perceptions towards key benefits and concerns from the future use of flying cars. Trav. Behav. Soc. 19, 54-66. doi:10.1016/j.tbs.2019.07.003

Shaheen, S., Cohen, A., Dowd, M., and Davis, R. (2019). A framework for integrating transportation into smart cities. Research Report 1705. CA: Mineta Transportation Institute.

Sinha, K. C., Labi, S., and Agbelie, B. R. D. K. (2017). Transportation infrastructure asset management in the new millennium: continuing issues, and emerging challenges and opportunities. Transp. A Transp. Sci. 13 (7), 591-606. doi:10. $1080 / 23249935.2017 .1308977$

Conflict of Interest: The authors declare that the research was conducted in the absence of any commercial or financial relationships that could be construed as a potential conflict of interest.

Copyright (C) 2021 Labi, Anastasopoulos, Miralinaghi, Ong and Zhu. This is an openaccess article distributed under the terms of the Creative Commons Attribution License (CC BY). The use, distribution or reproduction in other forums is permitted, provided the original author(s) and the copyright owner(s) are credited and that the original publication in this journal is cited, in accordance with accepted academic practice. No use, distribution or reproduction is permitted which does not comply with these terms. 